\title{
Analisa Decision Tree Untuk Menentukan Jadwal Kerja Karyawan Restoran Pada Hari Libur
}

\author{
Martini $^{1}$, Rian Septian Anwar ${ }^{2}$, Sari Masshitah ${ }^{3}$ \\ Fakultas Teknik dan Informatika \\ Universitas Bina Sarana Informatika Jakarta \\ martini.mtn@bsi.ac.id ${ }^{1}$,rian.ptn@bsi.ac.id ${ }^{2}$, sari.shh@bsi.ac.id ${ }^{3}$
}

\begin{abstract}
Abstrak: Pelayanan yang baik merupakan salah satu indikator bagi usaha restoran agar dapat memuaskan pelanggan. Semakin cepat pelanggan mendapatkan pelayanan terbaik dari restoran maka dapat meningkatkan margin penjualan. Hal ini juga berkaitan dengan loyalitas pelanggan yang diharapkan dapat membeli kembali di restoran tersebut. Restoran terlihat ramai pengunjung pada hari-hari libur sehingga pelayanan seluruh karyawan semakin bertambah sibuk. Pelayanan yang baik tidak terlepas dari peran manajemen restoran dalam membuat keputusan untuk mengatasi masalah di hari libur. Jika pelanggan tidak dilayani dengan baik maka dikhawatirkan pelanggan akan beralih ke restoran lain yang menyediakan produk sejenis. Penelitian ini bertujuan untuk menentukan kebutuhan jumlah karyawan khususnya di hari libur yang banyak dikunjungi pelanggan. Metode yang digunakan dalam penelitian ini adalah algoritma C4.5 untuk membangun Decision Tree yang menghasilkan keputusan sesuai masalah yang diteliti. Hasil dari penelitian ini berupa keputusan untuk mengatur jadwal shift karyawan atau menambah karyawan sesuai kebutuhan restoran khusus pada hari libur saja berdasarkan kedisiplinan karyawan.
\end{abstract}

Kata Kunci : manajemen restoran; decision tree; kedisiplinan karyawan.

Abstract: Good service is one indicator for a restaurant business to be able to satisfy customers. The sooner customers get the best service from the restaurant, the more sales margins can increase. This is also related to the loyalty of customers who are expected to repurchase at the restaurant. The restaurant looks crowded with visitors on holidays so that the service of all employees is getting busier. Good service cannot be separated from the role of restaurant management in making decisions to solve problems on holidays. If the customer is not served well, it is feared that the customer will switch to another restaurant that provides similar products. This study aims to determine the number of employees needed, especially on holidays that are visited by many customers. The method used in this study is the C4.5 algorithm to build a Decision Tree that produces decisions according to the problem under study. The results of this study are in the form of decisions to arrange employee shift schedules or add employees according to the needs of special restaurants on holidays only based on employee discipline.

Keywords: restaurant management; decision tree; employee discipline

\section{Pendahuluan}

Setiap perusahaan menginginkan karyawannya dapat bekerja secara maksimal sesuai dengan keahliannya masing-masing. Banyak sekali faktor-faktor yang mempengaruhi kinerja seorang karyawan, seperti umur, jenis kelamin, tingkat kedisiplinan, dll. Berdasarkan faktorfaktor tersebut, maka harus disusun sebuah jadwal kerja yang sesuai dengan kriteria masingmasing karyawan. Namun, muncul beberapa kendala apabila pembuatan jadwal kerja itu 
dilakukan secara manual. Salah satunya adalah jumlah karyawan yang besar. Dengan jumlah karyawan yang mencapai ratusan orang, akan sangat sulit untuk membuat jadwal kerja dengan mempertimbangkan kriteria dari masing-masing karyawan (Achmad, 2012).

Saat ini sektor kuliner menjadi perhatian bagi pelaku bisnis yang terus mengembangkan usaha bisnisnya mulai dari produk makanan dan minuman dengan harga kaki lima hingga yang tergolong mahal. Pelaku bisnis kuliner ini berlomba-lomba untuk membuat inovasi yang baru dalam menarik minat pembeli. Restoran juga melihat peluang ini untuk mengembangkan bisnisnya dan menjaga keparcayaan yang tinggi kepada pelanggannya. Oleh karena itu dibutuhkan pelayanan yang baik agar pelanggan merasa nyaman dan pastinya akan terus membeli. Kualitas pelayanan merupakan factor dan akar penting yang mampu memberikan kepuasan bagi pelanggannya. Sehingga pelanggan merasa puas dengan pelayanan yang diberikan (Sulistyawati, 2015).

Kualitas pelayanan yang baik dan prima untuk memenuhi pelayanan mampu untuk melindungi serta meningkatkan level pelayanan atau jasa pelayanan yang diberikannya, sehingga pelayanan atau jasa dari perusahaan akan terus dipakai oleh pelanggan karena merasa senang (Ismail, 2021). Hal ini tidak terlepas dari kerja sama tim pekerja di restoran seperti juru masak, pramusaji atau pelayan, karyawan yang membersihkan peralatan dan bahan makanan, serta kasir. Jika hal ini tidak dikelola dengan baik tentunya akan memengaruhi tingkat margin penjualan bisnis restoran.

Secara umum, tingkat kepuasan konsumen atau kepuasan pelanggan adalah tingkat perasaan konsumen setelah membandingkan harapannya dengan apa yang telah diterima dari produk atau jasa itu sendiri. Biasanya jika harapannya sesuai dengan apa yang ia dapatkan maka konsumen tersebut akan terus menggunakan jasa dari perusahaan tertentu (Stella, 2017). Hasil analisis data menunjukan bahwa keseluruhan variabel kualitas layanan (bukti fisik, kehandalan, daya tanggap, jaminan, dan empati) berpengaruh positif dan signifikan terhadap kepuasan pelanggan Restoran Baruna Sanur, selain itu terdapat perbedaan kepuasan antara pelanggan laki-laki dan perempuan terhadap pelayanan Restoran Baruna Sanur (Utami, 2015).

Keputusan yang menentukan apakah organisasi dapat menentukan atau mengembangkan sumber daya manusia sebaiknya diakukan secara terstruktur dan terhimpun dalam suatu sistem yang baik sehingga proses penentuannya dapat cepat dilakukan dan mengurangi kesalahankasalahan yang mungkin terjadi sebelumnya seperti kesalahan menunjuk seseorang yang tidak tepat dalam pekerjaannya. Seorang pekerja akan mampu mengambil keputusan yang baik bila dia memahami dan mampu dalam bidang ruang lingkup yang dia hadapi (Soetrisno, 2017).

\section{Metode Penelitian}

Untuk mendapatkan data kuantitatif digunakan metode penelitian survei yang cocok untuk memperoleh data khususnya data karakteriktik perilaku karyawan dalam memberikan pelayanan kepada pelanggan. Teknik pengumpulan data dilakukan dengan wawancara kepada juru masak dan pramusaji untuk mendapatkan informasi terkait pekerjaannya dalam melayani pelanggan pada hari kerja maupun hari libur. Ini dimaksudkan agar mendapatkan gambaran mengenai perbedaan antara layanan pada hari-hari tersebut. Selain itu untuk memperkuat penelitian ini juga dilakukan teknik studi pustaka dari referensi buku dan jurnal terkait tema yang dibahas guna memperoleh gambaran mengenai penelitian sejenis.

Langkah yang dilakukan untuk mendapatkan keputusan adalah dengan membuat analisa data yang diperlukan khususnya yang berkaitan dengan jadwal kerja. Data yang diperoleh dalam kurun waktu bulan Maret - April 2021 yang terdapat hari libur nasional. Data tersebut 
kemudian dianalisa untuk dibuat pengelompokkan, dan selanjutnya dibuat decision tree dengan algoritma C4.5. Pengujian data dengan Aplikasi Tanagra 1.4.50.

\section{Hasil dan Pembahasan}

Penelitian dilakukan pada restoran cepat saji di Jakarta yang menjual makanan dan minuman khas Itali. Meskipun selama ini jumlah karyawan dirasa sudah cukup memenuhi kinerja dalam pelayanan dan penyajian masakan, namun masih terdapat kendala dalam pelayanan di hari libur. Hari libur yang dimaksudkan adalah libur nasional dan libur biasa seperti hari Sabtu dan hari Minggu. Jika pembeli yang datang cukup banyak akan ada kesibukan di bagian dapur dalam menyiapkan dan memasak makanan dan membuat minuman yang dipesan, terlebih di bagian dapur juru masak sekaligus mencuci peralatan dan bahan makanan. Hal ini akan menyebabkan antrian pembelian baik untuk pelanggan yang makan di tempat maupun yang dibawa pulang.

\subsection{Pengelompokkan Data}

Data yang diperoleh masih berbentuk catatan di buku besar dan absen dengan mesin amano, sehingga data sehingga dilakukan penulisan ke dalam Microsoft Excel untuk diperoleh parameter yang akan diteliti. Berdasarkan data tersebut ditemukan bahwa ada kesenjangan antara kebutuhn karyawan di bagian dapur untuk mencuci dan menyiapkan bahan makanan atau minuman. Jika hari libur berlangsung beberapa hari maka karyawan akan mengalami kelelahan walaupun sudah dibuat jadwal shift dan memasukkannya ke dalam waktu lembur. Ini menjadi kendala Restoran untuk mengambil keputusan apakah membuat jadwal shift dengan jumlah karyawan yang ada atau menambah karyawan dengan status kontrak secara insedentil ketika waktu libur saja.

Data kemudian diklasifikasikan untuk menentukan kebutuhan karyawan. Pengelompokkan ini dimaksudkan agar manajemen restoran juga dapat mengatur jadwal kerja mengingat jumlah karyawan yang terbatas terlebih jika harus bekerja ekstra pada hari libur. Karyawan bisa saja untuk masuk kerja di hari libur Sabtu dan Minggu, namun untuk hari libur nasional di hari Jum'at atau hari Senin akan menjadi libur panjang. Walaupun kasus ini jarang terjadi tetapi sudah diantisipasi untuk penyelesaiannya sehingga perlu diatur jadwal kerja karyawan agar tidak lelah dan pelayanan dapat dimaksimalkan. Dari kebutuhan tersebut diperoleh beberapa data:

a. Atribut Karyawan yang mempunyai instance Juru Masak, Pramusaji, Petugas Kebersihan, dan Kasir

b. Atribut Hari Libur Biasa (HLB) yaitu hari Sabtu dan hari Minggu yang terbagi menjadi 2 shift yaitu pagi, dan malam.

c. Atribut Hari Libur Nasional (HLN) termasuk libur cuti bersama yang terbagi menjadi 2 shift yaitu pagi, dan malam..

d. Atribut Kedisiplinan yang mempunyai instance Baik, Cukup Baik, dan Kurang Baik. Kedisiplinan ini juga berpengaruh pada penentuan keputusan di tingkat manajemen terhadap karyawan.

e. Atribut yang merupakan prediksi dari keputusan adalah Mengatur Jadwal dan Tenaga Tambahan. 
Tabel 1. merupakan hasil klasifikasi data sesuai dengan atribut yang dijelaskan di atas setelah dimasukkan ke dalam Microsoft Excel.

Tabel 1. Pengelompokkan dan Prediksi Data Karyawan pada Hari Libur

\begin{tabular}{|c|c|c|c|c|c|c|}
\hline \multirow{2}{*}{ Jenis Karyw } & \multicolumn{2}{|c|}{ HLB } & \multicolumn{2}{|c|}{ HLN } & \multirow{2}{*}{ Disiplin } & \multirow{2}{*}{ Prediksi } \\
\hline & Shift 1 & Shift 2 & Shift 1 & Shift 2 & & \\
\hline Juru Masak 1 & Ya & Ya & Ya & Tidak & Cukup Baik & Atur Jadwal \\
\hline Juru Masak 2 & Ya & Ya & Ya & Tidak & Cukup Baik & Atur Jadwal \\
\hline Juru Masak 3 & Ya & Ya & Ya & Tidak & Baik & Tenaga tambahan \\
\hline Juru Masak 4 & Ya & Ya & Ya & Tidak & Baik & Tenaga tambahan \\
\hline Juru Masak 5 & Ya & Ya & Ya & Ya & Baik & Tenaga tambahan \\
\hline Juru Masak 6 & Ya & Ya & Ya & Ya & Baik & Tenaga tambahan \\
\hline Juru Masak 7 & Ya & Tidak & Ya & Ya & Cukup Baik & Atur Jadwal \\
\hline Juru Masak 8 & Ya & Ya & Ya & Ya & Cukup Baik & Tenaga tambahan \\
\hline Juru Masak 9 & Ya & Ya & Tidak & Ya & Cukup Baik & Atur Jadwal \\
\hline Juru Masak 10 & Ya & Tidak & Tidak & Ya & Kurang Baik & Atur Jadwal \\
\hline Pramusaji 1 & Ya & Ya & Ya & Tidak & Kurang Baik & Atur Jadwal \\
\hline Pramusaji 2 & Ya & Ya & Ya & Ya & Baik & Tenaga tambahan \\
\hline Pramusaji 3 & Ya & Ya & Ya & Ya & Baik & Tenaga tambahan \\
\hline Kasir 1 & Ya & Ya & Ya & Tidak & Baik & Atur Jadwal \\
\hline Kasir 2 & Ya & Ya & Tidak & Ya & Kurang Baik & Atur Jadwal \\
\hline Staff Kebersihan 1 & Ya & Ya & Ya & $\mathrm{Ya}$ & Baik & Tenaga tambahan \\
\hline Staff Kebersihan 2 & Ya & Ya & Ya & Ya & Baik & Tenaga tambahan \\
\hline
\end{tabular}

\subsection{Algoritma $\mathbf{C} 4.5$}

Data yang sudah dikelompokkan untuk selanjutnya dianalisa menggunakan Algoritma C4.5 untuk membangun decision tree. Berdasarkan Tabel 3.1 dilakukan beberapa langkah dan perhitungan yang bertujuan mengubah bentuk data dalam tabel menjadi model pohon (tree).

1. Menentukan Root atau akar dari pohon dengan cara menghitung nilay entropy kriteria sesuai data sampel yang telah ditentukan dengan rumus berikut:

$$
\operatorname{Entropy}(S)=\sum_{i=0}^{n}-p i x \log _{2} p i
$$

Untuk menentukan atribut sebagai akar adalah nilai Gain tertinggi yang dihitung dengan rumus berikut:

$$
\operatorname{Gain}(S, A)=\operatorname{Entropy}(S)-\sum_{i=1}^{n} \frac{\left|S_{i}\right|}{|S|} x \operatorname{Entropy}\left(S_{i}\right)
$$

Berdasarkan rumus di atas dapat dihitung Entropy dan Gain yang ditunjukkan pada tabel 2. 
Tabel 2. Perhitungan Entropy Untuk Node Akar

\begin{tabular}{|c|c|c|c|c|c|}
\hline & $\begin{array}{c}\text { Jml } \\
\text { Karyawan } \\
(\mathbf{S}) \\
\end{array}$ & $\begin{array}{c}\text { Atur } \\
\text { Jadwal } \\
\text { (S1) }\end{array}$ & $\begin{array}{c}\text { Tenaga } \\
\text { Tambahan } \\
\text { (S2) }\end{array}$ & Entropy & Gain \\
\hline TOTAL & 17 & 8 & 9 & 0.998 & \\
\hline HLB & & & & & 0.141 \\
\hline Kerja 1 Shift & 2 & 2 & 0 & 0.000 & \\
\hline Kerja 2 Shift & 15 & 6 & 9 & 0.971 & \\
\hline HLN & & & & & 0.337 \\
\hline Kerja 1 Shift & 9 & 7 & 2 & 0.764 & \\
\hline Kerja 2 Shift & 8 & 1 & 7 & 0.544 & \\
\hline Disiplin & & & & & 0.519 \\
\hline Baik & 0 & 1 & 8 & 0.503 & \\
\hline Cukup Baik & 5 & 4 & 1 & 0.722 & \\
\hline Kurang Baik & 3 & 3 & 0 & 0.000 & \\
\hline
\end{tabular}

Pada perhitungan awal yang menjadi node akar adalah atribut Disiplin yang mempunyai Gain terbesar.

2. Dengan cara yang sama, langkah selanjutnya adalah menentukan atribut hingga menghasilkan keputusan (daun), seperti ditunjukkan pada gambar berikut:

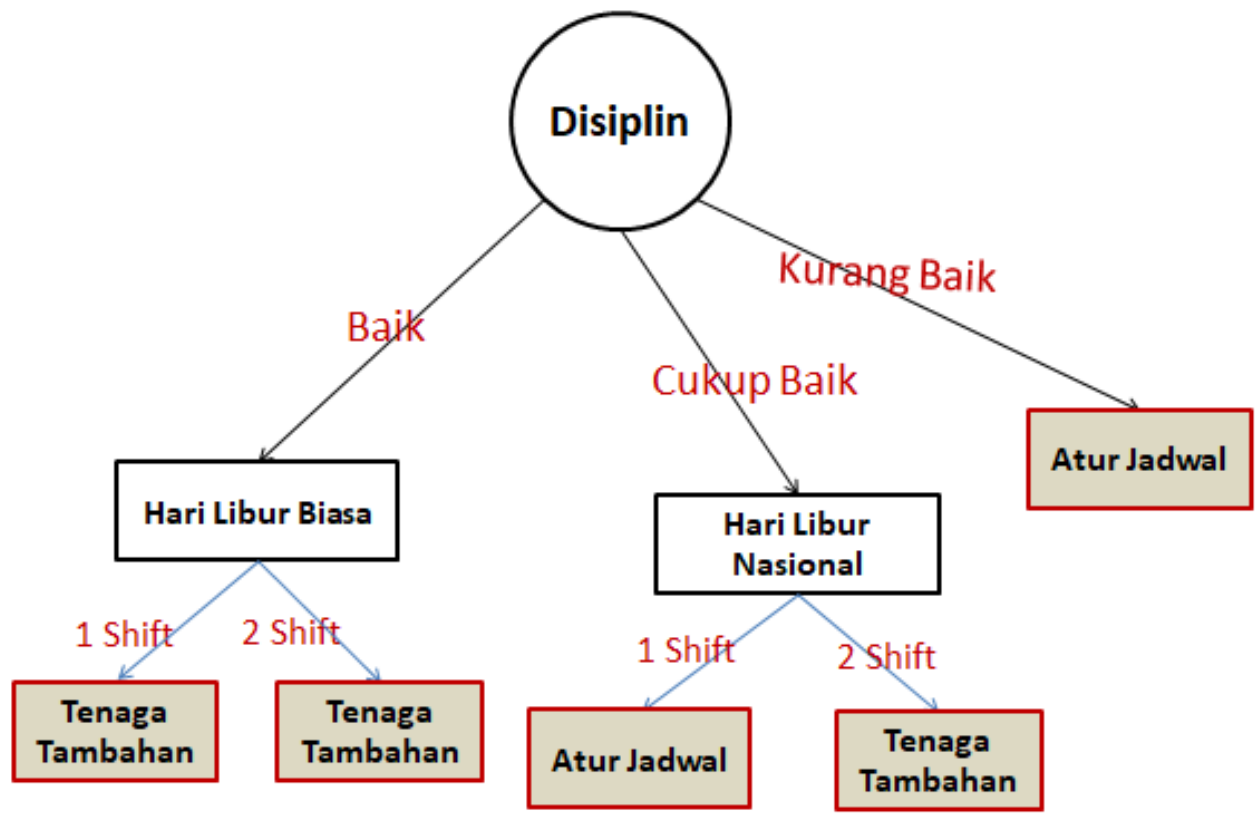

Gambar 1. Decision Tree Penentuan Kerja Karyawan

Gambar 1. masih terdapat nilai yang keputusannya melibatkan masukan dari manajemen, untuk karyawan yang bekerja 1 shift pada hari libur biasa dan 2 shift pada hari libur nasional. Indikator yang berpengaruh adalah kerja dengan shift pagi dan shift malam, hal ini juga sangat berpengaruh pada tingkat kesehatan karyawan. 
3. Langkah berikutnya mengubah Tree menjadi aturan (Rules) seperti pada Tabel 3:

Tabel 3. Hasil dari Decision Tree

\begin{tabular}{|c|c|c|}
\hline Rule & Aturan & Hasil \\
\hline $\mathbf{R 1}$ & IF Disiplin = Baik AND HLB = 1 Shift & $\begin{array}{l}\text { Tenaga } \\
\text { Tambahan }\end{array}$ \\
\hline $\mathbf{R 2}$ & IF Disiplin = Baik AND HLB $=2$ Shift & $\begin{array}{l}\text { Tenaga } \\
\text { Tambahan }\end{array}$ \\
\hline R3 & IF Disiplin $=$ Cukup Baik AND HLN $=1$ Shift & Atur Jadwal \\
\hline R4 & IF Disiplin = Cukup Baik AND HLN = 2 Shift & $\begin{array}{l}\text { Tenaga } \\
\text { Tambahan }\end{array}$ \\
\hline R5 & IF Disiplin = Kurang Baik & Atur Jadwal \\
\hline
\end{tabular}

Rule yang dihasilkan dapat diterapkan pada restoran, misalnya jika karyawan mempunyai disiplin yang baik dan bekerja pada hari libur Sabtu dan Minggu baik yang dilakukan 1 shift atau 2 shift diperlukan tenaga tambahan. Manajemen dapat mempertimbangkan hal ini untuk tenaga tambahan apa yang dibutuhkan.

\subsection{Melakukan Pengujian}

Pengujian yang akan dilakukan menggunakan Aplikasi Tanagra 1.4.50 untuk memastikan bahwa pembentukan decision tree sudah dapat diterima. Berikut hasil dari aplikasi tanagra:

1. Input data

Data pada Tabel 1 dibuat menjadi nilai numerik dimana untuk Shift-1 menjadi 1 dan Shift2 menjadi 2, sedangkan untuk nilai disiplin Baik menjadi 1, Cukup Baik menjadi 2, dan Kurang Baik menjadi 3 seperti ditunjukkan pada Gambar 2:

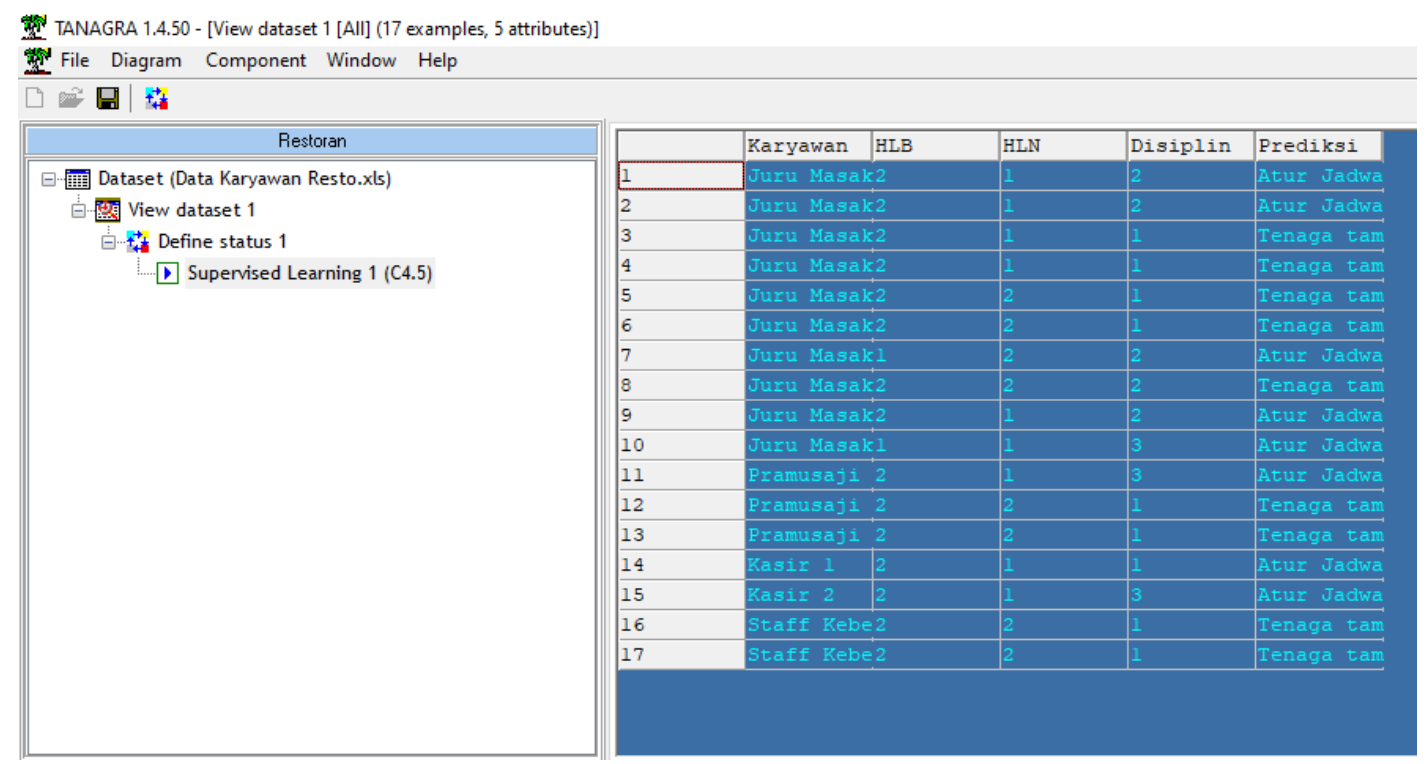

Gambar 2. Data Input pada Tanagra 
2. Tampilan Dataset

Dataset menampilkan informasi mengenai jumlah atribut dan data sampel yang akan dihitung. Lihat pada Gambar 3.

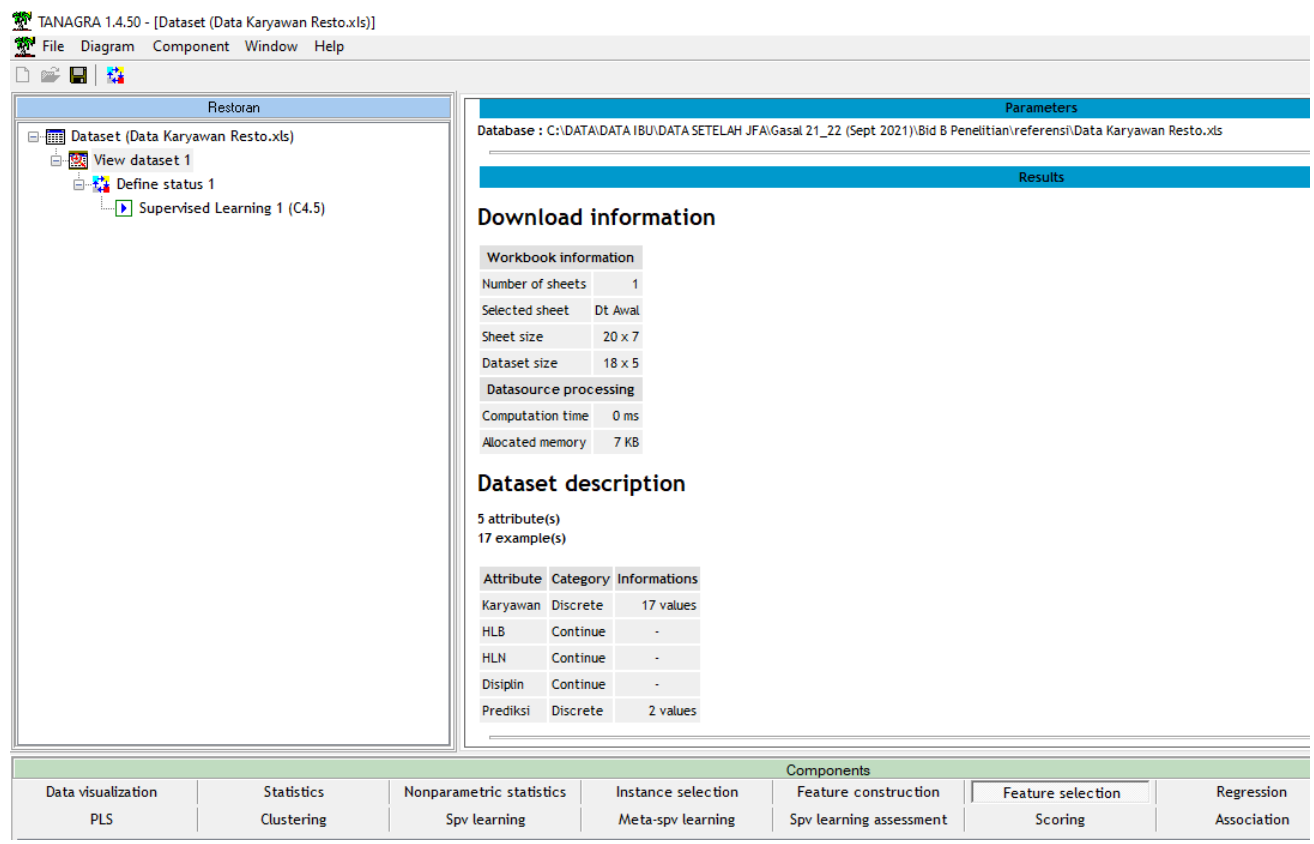

Gambar 3. Tampilan Dataset Tanagra

3. Tampilan Define Status

Define Status menjelaskan informasi mengenai berapa jumlah input dan target. Input adalah Karyawan, HLB, HLN dan Disiplin, sedangkan target adalah Prediksi.

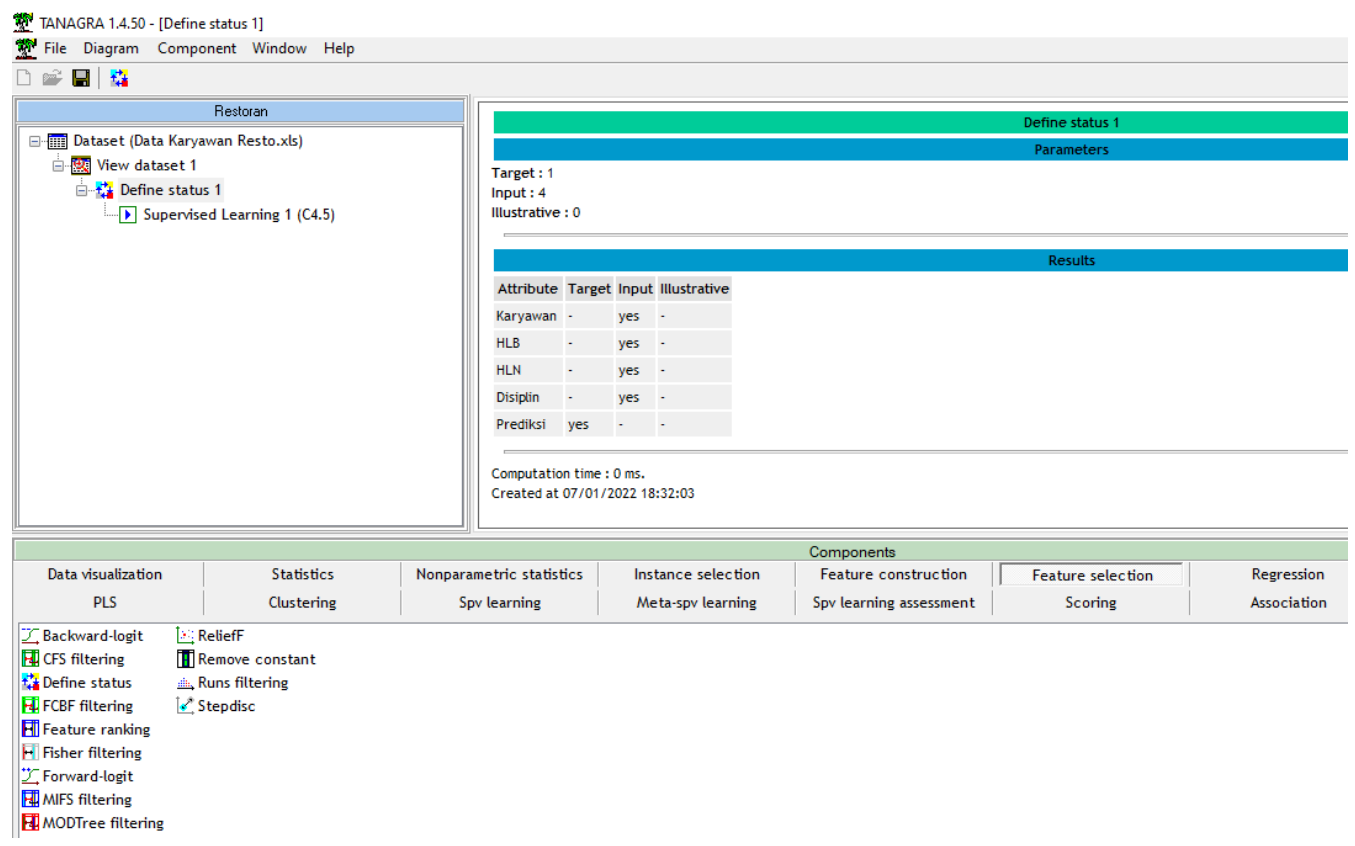




\section{Gambar 4. Tampilan Define Status Tanagra}

4. Tampilan Supervised Learning

Supervised Learning menampilkan hasil perhitungan confusion matrix dan hasil dari decision tree. Nilai yang dihasilkan pada confusion matrix dapat diterima dengan nilai yang mendekati 1.

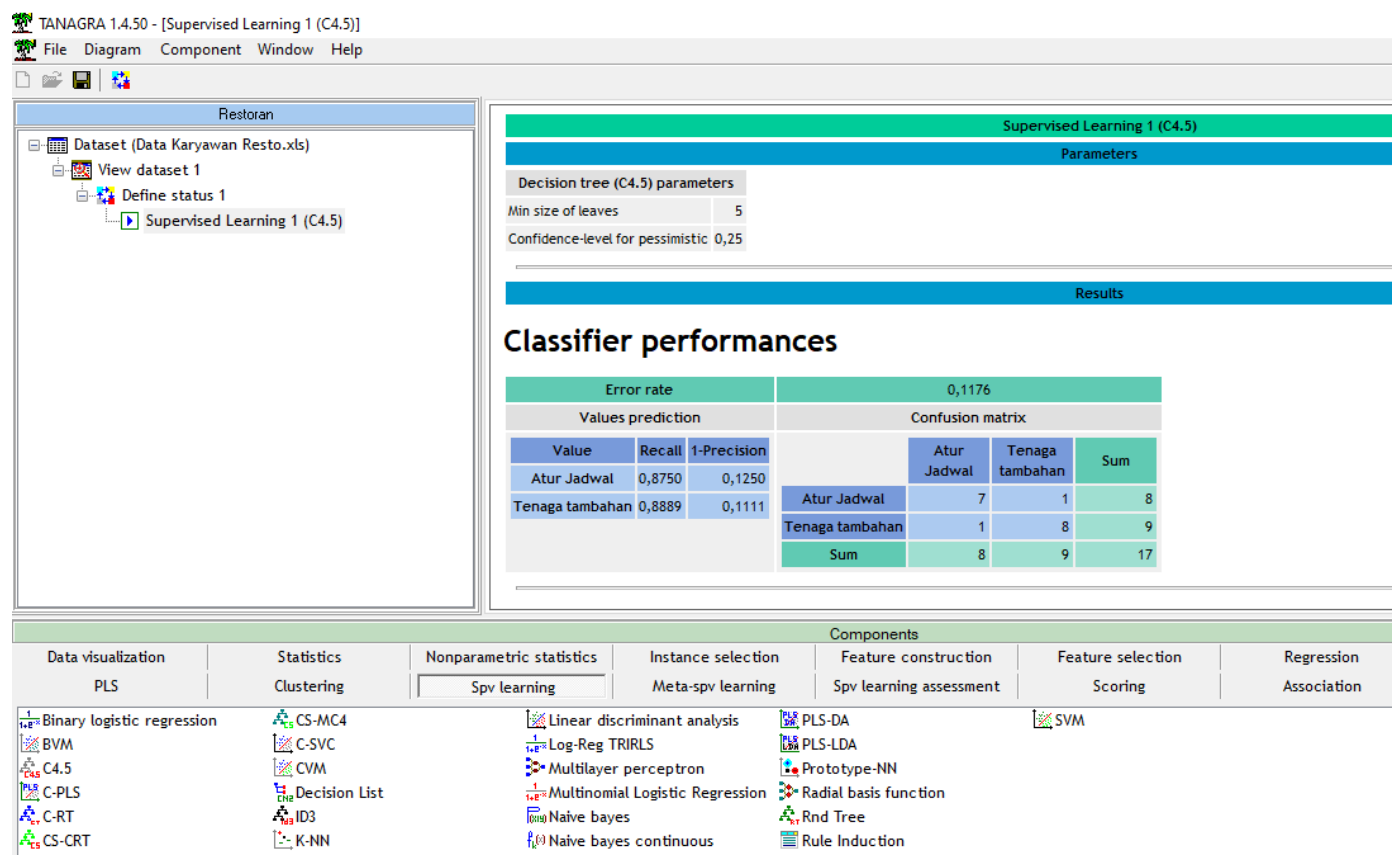

Gambar 5. Tampilan Hasil Uji Coba dengan Confusion Matrix Tanagra 


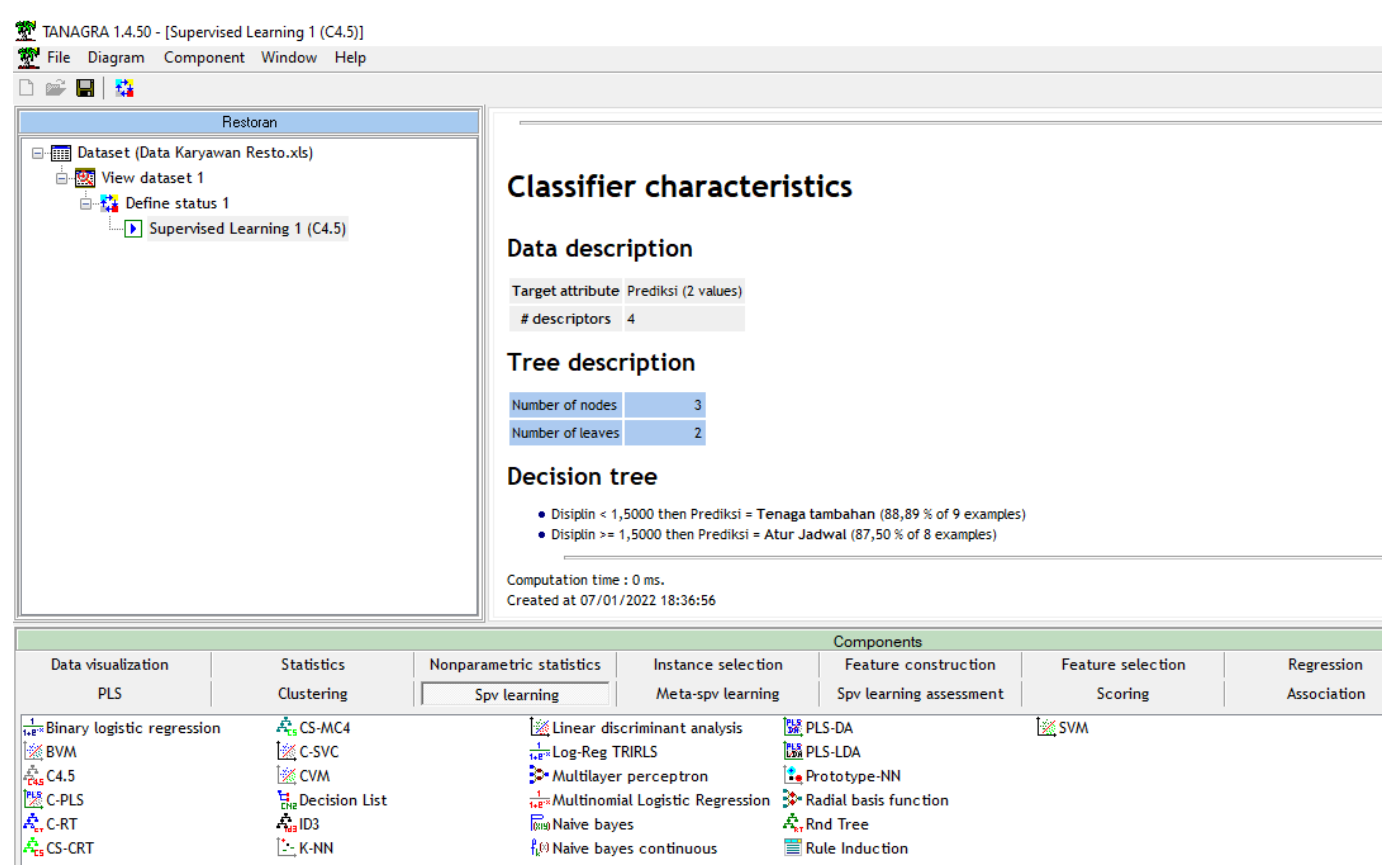

Gambar 6. Tampilan Hasil Decision Tree Tanagra

\section{Kesimpulan dan Saran}

Data yang telah dianalisa dengan menerapkan Algoritma C4.5 serta dilakukan pengujian menggunakan Aplikasi Tanagra dapat diambil kesimpulan Pembentukan Decision tree dengan penerapan Algoritma C4.5 dalam menentukan keputusan terhadap kebutuhan karyawan pada restoran di hari libur merupakan salah satu cara yang tepat untuk membantu manajemen restoran dalam mengambil keutusan. Pengujian dengan aplikasi Tanagra dapat dapat membantu mendapatkan hasil yang mendekati kesamaan dengan penerapan Algoritma C4.5

Saran yang dapat diberikan kepada pihak restoran adalah memberikan perhatian kepada karyawan sehingga loyalitas karyawan menjadi meningkat yang tentunya berimbas pada usaha restoran yang berkelanjutan.

\section{Daftar Pustaka}

Achmad, Budanis Dwi Meilan. Fauzi Slamat. (2012). Klasifikasi Data Karyawan Untuk Menentukan Jadwal Kerja Menggunakan Metode Decision Tree. Jurnal IPTEK. Vol 16. No.1. pp. 17-23.

Budiman, Ade Surya. Xanty Adhi Parandani. (2018). Uji Akurasi Klasifikasi dan Validasi Data pada Penggunaan Metode Membership Function dan Algoritma C4.5 Dalam Penilaian Penerimaan Beasiswa. Jurnal SIMETRIS, Vol. 9 No. 1.pp. 565-578

Ismail, Taupik. Ramayani Yusuf. (2021). Pengaruh Kualitas Pelayanan Terhadap Kepuasan Pelanggan Kantor Indihome Gegerkalong di Kota Bandung. Jurnal Ilmiah MEA. Vol. 5. No. 3. pp. 413-423. 
Maimon, Oded. Lior Rokach. (2010). Data Mining and Knowledge Discovery Handbook. from https://www.researchgate.net/publication/236005657_Data_Mining_and_ Knowledge_Discovery_Handbook_2nd_ed.

Smith, Gillian. 2010, Tanagra: A mixed-initiative level design tool. From https://www.researchgate.net/publication/228339816_Tanagra_A_mixedinitiative_level_design_tool

Soetrisno, Edy. (2017). Manajemen Sumber Daya Manusia. Kencana: Jakarta

Stella, Eko Harry Susanto. (2017). Analisis Kualitas Pelayanan Pada Restoran XYZ Dalam Rangka Mengukur Kepuasan Pelanggan. Jurnal Manajemen Bisnis dan Kewirausahaan. Vol.1. no. 1. pp. 8-16.

Sulistyawati, Ni Made Arie. Ni Ketut Seminari. (2015). Pengaruh Kualitas Pelayanan Terhadap Kepuasan Pelanggan Restoran Indus Ubud Gianyar. E-Jurnal Manajemen Unud. Vol. 4. No. 8. pp. 2318-2332.

Utami, Ida Ayu Inten Surya. I Made Jatra. (2015). Pengaruh Kualitas Layanan Terhadap Kepuasan Pelanggan Restoran Baruna Sanur. E-Jurnal Manajemen Unud. Vol. 4. No. 7. pp. 1984-2000.

Yuliana, Ade. Duwi Bayu Pratomo. (2017). Algoritma Decision Tree (C4.5) Untuk Memprediksi Kepuasaan Mahasiswa Terhadap Kinerja Dosen Politeknik TEDC Bandung. pp. 377-384.

Zega, Selly Artaty. (2014). Penggunaan Pohon Keputusan untuk Klasifikasi Tingkat Kualitas Mahasiwa Berdasarkan Jalur Masuk Kuliah. Seminar Nasional Aplikasi Teknologi Informasi (SNATI). pp. 7-13. 